\title{
Maternal mortality: a tertiary care hospital experience in Upper Egypt
}

\author{
Ahmed M. Abbas*, Mariam T. Amin, Shymaa S. Ali, Neima Z. Salem
}

\author{
${ }^{1}$ Department of Obstetrics and Gynaecology, Assiut University, Egypt \\ ${ }^{2}$ Department of Public Health, Assiut University, Egypt
}

Received: 04 March 2016

Accepted: 30 March 2016

\section{*Correspondence:}

Dr. Ahmed M. Abbas,

E-mail: bmr90@hotmail.com

Copyright: ( ) the author(s), publisher and licensee Medip Academy. This is an open-access article distributed under the terms of the Creative Commons Attribution Non-Commercial License, which permits unrestricted non-commercial use, distribution, and reproduction in any medium, provided the original work is properly cited.

\begin{abstract}
Background: Maternal mortality is one of the major challenges which face the developing countries throughout the world. The aim of the study is to assess the causes of maternal mortality at Women Health Hospital, Assiut University, Egypt, and to identify the avoidable ones.

Methods: Data were collected from records of patients who presented to and/or delivered at Women Health Hospital between 2009 and 2014. Only cases of maternal mortality were included in this study. In our study, we found 213 maternal deaths at our hospital between 2009 and 2014.

Results: The maternal mortality ratio decreased progressively from 2009 to 2014 (228 and 89 per 100000 live birth respectively). Moreover, we found that the indirect causes of maternal mortality accounted for $24.9 \%$ of all mortalities. As regards the direct causes of maternal mortality, preeclampsia remained the primary cause and represented $27.7 \%$ of the avoidable causes. The second most frequent cause of direct maternal mortality was postpartum hemorrhage (PPH), which represented $26.8 \%$.

Conclusions: Preeclampsia and PPH, as well as their complications are the leading causes of death in one of the biggest tertiary care university hospitals in Egypt. However, there are other important avoidable predisposing factors that should be dealt with including lack of patient education, delayed transfer from other hospitals, and substandard practice.
\end{abstract}

Keywords: Developing countries, Health facilities, Preeclampsia, Postpartum hemorrhage, Maternal mortality

\section{INTRODUCTION}

Maternal mortality is one of the major challenges which face the developing countries throughout the world. According to the tenth revision of the international classification of diseases (ICD-10) it is defined as the death of a woman while pregnant or within 42 days of termination of pregnancy, irrespective of the duration and to the site of the pregnancy, from any cause related to or aggravated by the pregnancy or its management but not from accidental or incidental causes. ${ }^{1}$ The 42 -day limit is somewhat arbitrary, and in recognizing the fact that modern life-sustaining procedures and technologies can delay death, ICD-10 introduced a new category, namely the late maternal death, which is defined as the death of a woman out of direct or indirect obstetric causes more than 42 days but less than one year after the termination of pregnancy. ${ }^{2}$ Maternal mortality ratio is defined as the number of women who died while pregnant or within 42 days of termination of pregnancy per 100,000 live births. ${ }^{3}$

Maternal deaths are divided into two groups. The first group is the direct obstetric deaths which result from obstetric complications during pregnancy, labour and the puerperium, or resulted from interventions, and any incorrect treatment received. The second group is the indirect deaths which are the result from previous existing disease or disease that developed during 
pregnancy and which were not due to direct obstetric causes, but was aggravated by physiologic effects of pregnancy. 4 Deaths from "accidental or incidental" causes have historically been excluded from maternal mortality statistics.

According to the WHO, $80 \%$ of maternal deaths in developing countries are due to direct maternal causes such as haemorrhage, sepsis and hypertensive disorders. Additionally, indirect causes such as HIV/AIDS, cardiac diseases, hepatic diseases and anemia account for the remaining $20 \%$ of maternal deaths. ${ }^{5}$ Of the 287,000 deaths due to pregnancy or childbirth complications that occur each year worldwide, $85 \%$ are in Africa and Asia alone. ${ }^{4}$

The difference in maternal mortality between developed countries (lifetime risk of maternal death is 1 in 3800) and developing countries (life time risk of maternal death is 1 in 150) is one of the highest differentials in public health. In Egypt the overall maternal mortality ratio is $32.6 / 100.000 .^{6}$

As $90 \%$ of maternal deaths are preventable, access to good quality essential obstetrical care can prevent $48 \%$ of maternal deaths at time of delivery. ${ }^{7}$ It is cost effective to invest in policy makers that reduce maternal mortality in the most efficient manner possible. ${ }^{8}$

Regarding the most riskiest time for maternal death, it seems that the most maternal deaths occur between third trimester and the first week after delivery. This risk is extremely high on the first and second days after delivery. 3,9 These findings provide strong support for prioritization of strategies that focus on professional intrapartum care.

There are three types of delay in emergency care for the pregnant women according to the framework presented by Thaddeus and Maine. ${ }^{10}$ The first delay is that delay caused by family and woman to recognize the need for medical help. The second delay is caused because of the late referral, so the woman arrives at the hospital too late to get a benefit from emergency care. The third delay is that due to the delay in receiving effective interventions after arriving at the hospital. ${ }^{11}$ Avoidable causes of maternal deaths are referred to as departure from the standard of satisfactorily accepted care by the woman, practitioner or institution/expected at a particular level of care, which may have contributed to the death. ${ }^{12}$

In this study, we estimated the maternal mortality burden in the largest tertiary care university hospital in Upper Egypt. Our aim was to search for the causes of maternal deaths, calculate the maternal mortality ratio and identify the avoidable causes and demographic factors for maternal mortality.

\section{METHODS}

This is a retrospective observational study conducted at Assiut women health hospital, which is the largest maternal tertiary care center in upper Egypt providing health services for seven governorates from January 2009 till December 2014.

Data were collected from the files of pregnant women admitted to the hospital. Inclusion criteria were death of a pregnant woman while she was pregnant or within 42 days from giving birth, including late maternal deaths which occurred more than 42 days but less than one year after termination of pregnancy, whether she was delivered inside or outside our hospital. The number of live births in the same period was obtained from the hospital logbooks. The ethical review board of Assiut faculty of medicine approved the study.

Data analysis was carried out, and the maternal mortality ratio was measured by dividing the number of maternal deaths by the number of live births during the period of the study multiplied by 100,000 . The data obtained were compared and analyzed using SPSS Inc., (Statistical program for social science Inc.,) Chicago, IL, USA, version. ${ }^{16}$ Variables were expressed as frequency and percentage. Chi-square test and binomial test were used to compare variables. Level of significance "P" value was evaluated, where $\mathrm{P}$ value $<0.05$ was considered statistically significant.

\section{RESULTS}

During the period of the study, a total of 125349 pregnant women were admitted to Assiut Women Health Hospital. The total number of live births was 94,196. Two-hundred and thirteen cases of maternal deaths were identified during study period. It was evident that the maternal mortality ratio, had decreased progressively from 228 in 2009 to 89 in 2014 (P-value <0.001) (Table 1). The leading cause of death in the 6 years was preeclampsia with its complications $(27.7 \%)$. The second cause was the uncontrollable postpartum haemorrhage $(26.8 \%)$, and the rest of the causes; direct and indirect accounted for $45.5 \%$. Direct maternal deaths accounted for $75.1 \%$ of all maternal deaths while $24.9 \%$ of maternal deaths were due to indirect causes (Figure 1).

When we analyzed the demographic characteristics of maternal deaths we found that the mean age of maternal deaths were $28.9 \pm 6.58$ years with significant differences between age groups (P-value $<0.0001)$. The mean of women's age who gave birth in our hospital was $27.3 \pm 6.98$ with no statistically significant difference with the mean age of maternal deaths $(\mathrm{P}$-value $=0.23)$. The mean parity of maternal deaths was $3.12 \pm 1.56$, and deaths among women parity $\leq 4$ were significantly higher than grand multiparous women with parity $>5$ (P-value $<0.0001)$ (Table2). 
Table 1: Total live birth in each year with maternal mortality ratio at Women Health Hospital in the study period.

\begin{tabular}{|lllllll|}
\hline Year & Total live births & $\begin{array}{l}\text { Inside the } \\
\text { hospital* }\end{array}$ & $\begin{array}{l}\text { Outside the } \\
\text { hospital }\end{array}$ & $\begin{array}{l}\text { Late maternal } \\
\text { deaths }\end{array}$ & Total & $\begin{array}{l}\text { MMR** per } \\
\text { live birth }\end{array}$ \\
\hline $2009^{1}$ & 11858 & 27 & 3 & 0 & 30 & 228 \\
\hline 2010 & 13398 & 28 & 5 & 2 & 35 & 209 \\
\hline 2011 & 15569 & 34 & 4 & 2 & 40 & 218 \\
\hline 2012 & 16220 & 33 & 8 & 1 & 42 & 203 \\
\hline 2013 & 18091 & 31 & 6 & 2 & 49 & 171 \\
\hline 2014 & 19060 & 17 & 7 & 3 & 27 & 89 \\
\hline Total & 94196 & 170 & 33 & 10 & 213 & 180 \\
\hline
\end{tabular}

* Either delevired or not; ** MMR: Matermal Mortality Ratio; *** MMR $=\frac{\text { Material deaths inside the hospital }}{\text { Total live borths inside the hospital }} \times 100,000 ; 1 * \mathrm{P}-\mathrm{value}$ calculated to detect the defferance between MMR in 2009 and 2014; it is $<0.0001$.

Table 2: Demographic characteristics for maternal deaths in the study period.

\begin{tabular}{|c|c|c|}
\hline & Frequency (\%) & P-value* \\
\hline \multicolumn{3}{|c|}{ Age groups (years) } \\
\hline$<20$ & $11(5.2 \%)$ & \multirow{4}{*}{$<0.0001$} \\
\hline $20-29$ & $108(50.7 \%)$ & \\
\hline $30-39$ & $72(33.8 \%)$ & \\
\hline$>40$ & $22(10.3 \%)$ & \\
\hline \multicolumn{3}{|c|}{ Gravidity and parity } \\
\hline$\leq \mathrm{G} 4$ & $171(80.3 \%)$ & \multirow{2}{*}{$<0.0001$} \\
\hline$>\mathrm{G} 5$ & $42(19.7 \%)$ & \\
\hline \multicolumn{3}{|l|}{ Residence } \\
\hline Urban & $59(27.7 \%)$ & \multirow{2}{*}{$<0.0001$} \\
\hline Rural & $154(72.3 \%)$ & \\
\hline \multicolumn{3}{|l|}{ Education } \\
\hline No education & $172(80.8 \%)$ & \multirow{2}{*}{$<0.0001$} \\
\hline Primary & $41(19.2 \%)$ & \\
\hline
\end{tabular}

*P-value by Chi-square test and binomial test.

Table 3: Distribution of maternal deaths regarding place, time and pregnancy outcome in the study period.

\begin{tabular}{|c|c|c|c|}
\hline \multicolumn{2}{|c|}{+2} & Frequency & $\%$ \\
\hline \multicolumn{4}{|c|}{ Place of death } \\
\hline \multicolumn{2}{|c|}{ Women Health Hospital } & 200 & 93.9 \\
\hline \multicolumn{2}{|c|}{ Outside the hospital } & 13 & 6.1 \\
\hline \multicolumn{4}{|c|}{ Time of death } \\
\hline \multicolumn{2}{|c|}{ During pregnancy } & 30 & 14.1 \\
\hline \multirow{2}{*}{$\begin{array}{l}\text { Day of } \\
\text { delivery }\end{array}$} & During labor & 22 & 10.3 \\
\hline & After labor & 29 & 13.6 \\
\hline \multirow{2}{*}{$\begin{array}{l}\text { Postpartum } \\
\text { (within } 42 \\
\text { days) }\end{array}$} & $\begin{array}{l}\text { 1-7 days after } \\
\text { delivery }\end{array}$ & 77 & 36.1 \\
\hline & $\begin{array}{l}\text { 8-42 days after } \\
\text { delivery }\end{array}$ & 45 & 21.1 \\
\hline \multicolumn{2}{|c|}{ Late maternal deaths } & 10 & 4.7 \\
\hline \multicolumn{4}{|c|}{ Pregnancy outcome } \\
\hline \multicolumn{2}{|c|}{ Not delivered } & 30 & 14.1 \\
\hline \multicolumn{2}{|c|}{ Abortion / stillbirth } & 31 & 14.6 \\
\hline \multicolumn{2}{|l|}{ Living } & 152 & 71.4 \\
\hline
\end{tabular}

Table 4: Place and mode of delivery for cases of maternal deaths in the study period.

\begin{tabular}{|c|c|c|c|}
\hline $\begin{array}{l}\text { Place of } \\
\text { delivery }\end{array}$ & $\begin{array}{l}\text { Inside the } \\
\text { hospital }\end{array}$ & $\begin{array}{l}\text { Outside the } \\
\text { hospital }\end{array}$ & P-value* \\
\hline Number & $144(78.7 \%)$ & $39(21.3 \%)$ & $<0.0001$ \\
\hline \multicolumn{4}{|c|}{ Delivered by health professional } \\
\hline Yes & $142(77.6 \%)$ & $0(0 \%)$ & \multirow{2}{*}{$<0.0001$} \\
\hline No & $2(1.1 \%)$ & $39(21.3 \%)$ & \\
\hline \multicolumn{4}{|c|}{ Mode of delivery } \\
\hline Vaginal & $71(38.8 \%)$ & $25(13.7 \%)$ & \multirow[b]{2}{*}{0.101} \\
\hline $\begin{array}{l}\text { Cesarean } \\
\text { section }\end{array}$ & $73(39.9 \%)$ & $14(7.6 \%)$ & \\
\hline
\end{tabular}

*P-value by Chi-square test.

Maternal deaths among illiterate women and those who live in rural areas were also significantly higher than those who received at least a primary education or lived in urban areas (P-value <0.0001) (Table 2).

Regarding the place and time of death, there were 13 cases of maternal deaths died on their way to the hospital and reached the hospital dead with failed trials of cardiopulmonary resuscitation. Two-hundred cases died inside the hospital; 30 cases during pregnancy most of them were in their third trimester, but the majority of the cases died postpartum $(75.6 \%)$, only 10 cases of them stayed more than 42 days on mechanical ventilator and considered as a late maternal deaths. Fifty-one women died on the day of the delivery, while 77 stayed for 1 week before death (Table 3).

When we analyzed the place of delivery, we found that only 39 cases of maternal deaths delivered outside our hospital either at home, private clinics or secondary health care hospitals. Most of the cases were delivered at our hospital with significant statistical difference (Pvalue $<0.0001)$. About $86.3 \%$ of the cases were delivered by health professional while the rest of the cases were delivered spontaneously without assistance or by a traditional birth attendant. No statistically significant difference in mortality between those who delivered vaginally or by caesarean section $(\mathrm{P}$-value $=0.101)$ (Table 4). 


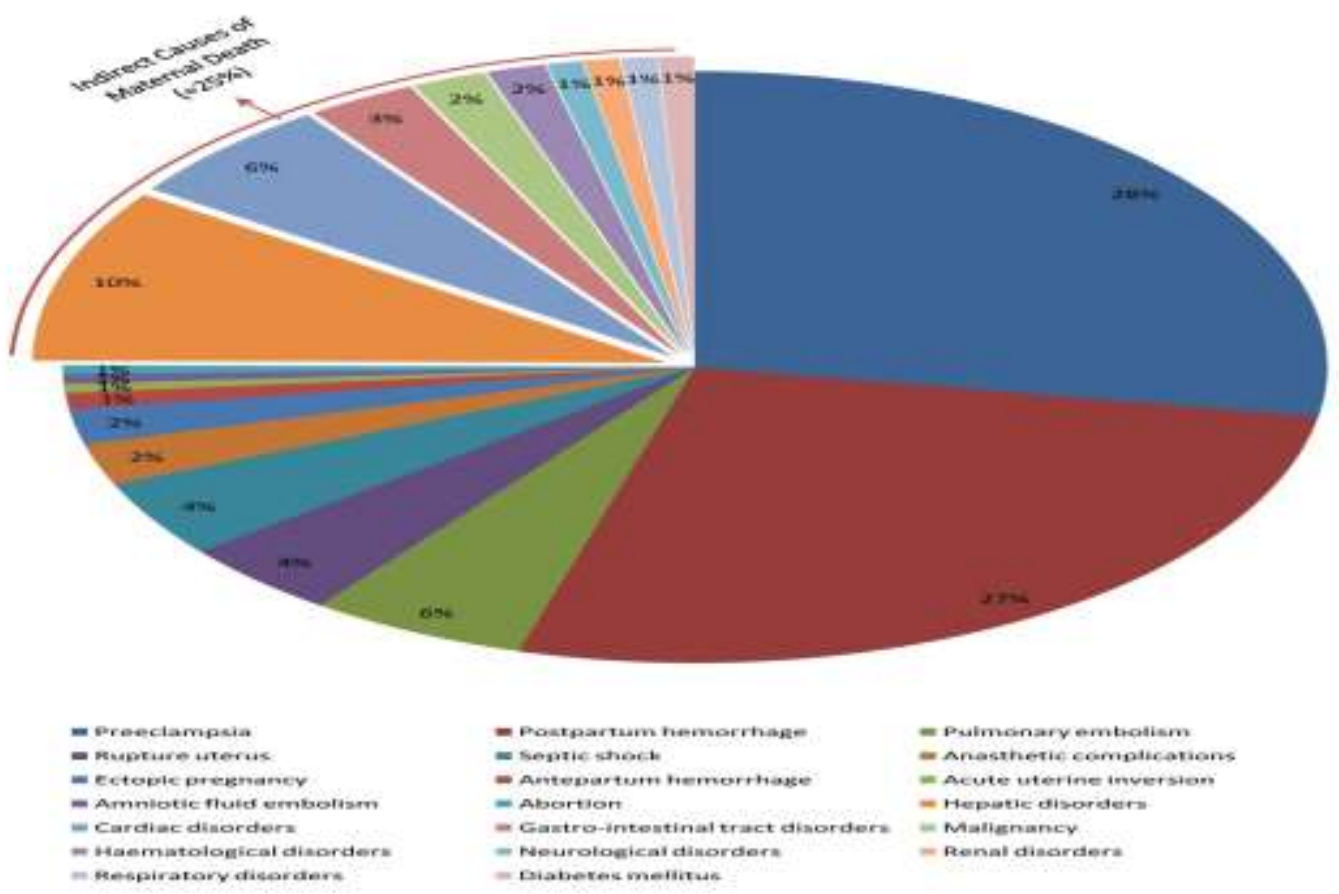

Figure 1: Causes of maternal deaths and its percentages at women health hospital between 2009 and 2014.

\section{DISCUSSION}

Developing countries account for 99\% (284 000) of the global maternal deaths reported in 2010 , the majority of which are in sub-Saharan Africa (162 000). Global MMR declined from 400 maternal deaths per 100000 live births in 1990 to 2010 in 2010. The MMR in developing regions is 240 maternal deaths per 100000 live births which were 15 times higher than in developed regions; only 16 deaths per 100,000 live births. ${ }^{4}$

There were four major causes of maternal death: hypertensive disorders, obstetric hemorrhage (mainly postpartum hemorrhage), infections and obstructed labor. In addition, it was found that women also die because of poor nutritional status at conception and because the substandard care provided to them. Current studies show that maternal deaths in developing countries could be reduced if all pregnant women could receive an emergency care of good quality. ${ }^{13}$

This coincides with the results obtained from our study, as we found that the main cause of death in the 6 years was preeclampsia with its consequences (27.7\%) followed by uncontrolled postpartum hemorrhage $(26.8 \%)$. In our study, we found a significant percentage of maternal deaths $(24.9 \%)$ are attributed to medical diseases not unique to pregnancy. Hepatic disorders accounted for $9.5 \%$ of maternal deaths especially acute fatty liver and acute fulminant hepatitis, while cardiac disorders came second $(5.6 \%)$ attributed to high prevalence of rheumatic heart diseases among Egyptian population.

We detected two main factors that contributed to maternal deaths in Women Health Hospital, and both could be avoided: first was the substandard care provided due to inadequate supplies and drugs, lacking in staffing and difficulties in communication between departments involved in the management of these cases, such as the intensive care unit, anesthesiology department, and blood bank. The second factor was delayed transfer from the private clinics, primary or secondary health care hospitals.

Although most of deliveries and abortions that resulted into a maternal death took place inside the hospital, only 60 cases sought medical advice directly to our hospital. This might be an indicator of delaying in recognition of complications, making a decision to go to a tertiary health care facility, and reaching it or receiving care while at the facility. Another problem is the lack of emergency ambulance services in the rural areas where infrastructure does not exist which delays referral. ${ }^{14}$ An earlier hospital assessment study that was done in Assiut Women Health Hospital showed that more than half of obstetric emergencies arrive at referral facilities by public means or their own cars. 
Maternal mortality studies showing differences between urban and rural areas especially in the poor countries. In Egypt, the maternal mortality ratio was high in the nomadic Frontier region than in the Metropolitan region (125 versus 54). ${ }^{15}$ In our study there were significant difference in maternal mortality among rural areas; 154 cases versus 59 cases only in urban areas ( $\mathrm{P}$ - value $<0.0001)$. This can be attributed to poverty and lack of transfer facilities from far villages, besides the higher rates of illiteracy among people than those living in urban areas.

Woman's education also is an important factor; as educated woman can determine the risks and complications early and usually aware about health services more than the illiterate woman. ${ }^{16}$ In our study we found this maternal death were significantly higher among illiterate women ( $\mathrm{P}$ - value <0.0001).

Most maternal deaths seem to occur between the third trimester and the first week after the end of pregnancy. ${ }^{3,9}$ Mortality is extremely high on the first and second days after birth. The results obtained from our study coincided with the published data. Nineteen cases out of 30 cases died during pregnancy were at their third trimester, 51 cases died on their first day after birth. These findings provide strong support for prioritization of strategies that focus on professional intrapartum care.

The risk of maternal death remains for some time after delivery. Maternal deaths defined as those occurring up to 42 days postpartum, although recently the late maternal death category has been introduced to include deaths up to 1 year postpartum. This change in definition is important since there is evidence that risk of death is increased for up to 6 months postpartum. ${ }^{2}$ In our study there were 10 cases of late maternal deaths, the longest case died 116 days after delivery due to brain stem hemorrhage resulted from eclamptic fits.

The maternal mortality ratio shows significant decrease in Assiut Women Health Hospital, Egypt over the period of the study reaching its lowest level in 2014 (P-value $<0.001)$. This can be attributed to increasing in workforce to include three running operative rooms with eight obstetricians working daily the supervision of a senior staff and equipped with an ultrasound machine. An intensive care unit was established with twelve beds equipped with all facilities with intensive monitoring and highly skilled nurses and residents available twenty-four hours per day. The hospital own blood bank which was established in 2013 to facilitate the supply of blood and blood products to all obstetric cases. This helped significantly in decreasing maternal mortality ratio from 2013.

Moreover, regulations were established in our hospital to guarantee the availability of a senior staff twenty-four hours per day all over the week in the obstetric emergency unit to save time when emergency cases are brought to the hospital. Improvements have been made in the full reporting of maternal deaths and maternal mortality surveillance systems have been installed. In addition, a review committee was established in 2013 for analysis and discussion of any maternal mortality in addition to developing strategies for prevention of avoidable factors of maternal mortality.

Although, the above factors have led to a significant decrease in the maternal mortality ratio they are still not enough as this only decreases the third delay which is the delay in the receiving effective intervention. The first delay, which is the delay caused by family and woman to recognize the need for medical help can be avoided by increasing the community awareness, by informing the pregnant woman about risks of her pregnancy and encouraging her to receive antenatal care. This will help in decreasing most of the indirect causes of maternal deaths. The second delay because of late referral, can be prevented by improving health system especially primary care centers, ambulance services and infrastructure which is some sort difficult and need long-term national plan. $^{11,17}$

One of the limitations of our study that it only reflects the cases that were brought to our hospital and thus may be a biased sample of the general population making our data not completely generalizable.

Saving maternal lives is a matter of human right and equality and as Professor Mahmoud Fathalla, past president of the international federation of obstetricians and gynecologists and former chair of the WHO advisory committee on health research, said: "women are not dying because of untreatable diseases. They are dying because societies have yet to make the decision that their lives are worth saving."18

\section{CONCLUSIONS}

The maternal mortality ratio in Assiut, Egypt women health hospital has been significantly decreased from 2009 to 2014. Preeclampsia and postpartum haemorrhage are still the most two leading causes of death in developing countries. Moreover, there were two major contributing factors in these deaths: the substandard care and delayed transfer of cases; both are avoidable. Efforts should be made to ensure that all deliveries occur with the help of skilled personnel.

\section{Funding: No funding sources Conflict of interest: None declared \\ Ethical approval: The study was approved by the Institutional Ethics Committee}

\section{REFERENCES}

1. World health organization. ICD-10: international statistical classification of diseases and related health problems. Geneva: world health organization; 1992. 
2. Høj L, da Silva D, Hedegaard K, Sandstrom A, Aaby P. Maternal mortality: only 42 days? BJOG 2003;110(11):995-1000.

3. Ronsmans C, Graham WJ. Maternal mortality: who, when, where, and why. Lancet. 2006;368:1189-200.

4. World health organization. Trends in maternal mortality: 1990 to 2010: WHO, UNICEF, UNFPA and the world bank estimates. Geneva: world health organization; 2012.

5. Buekens P. Is estimating maternal mortality useful? Bull world health organ. 2001;79(3):179.

6. Kassebaum NJ, Villa AB, Coggeshall MS, Shackelford KA, Steiner C, Heuton KR, et al. Global, regional, and national levels and causes of maternal mortality during 1990-2013: a systematic analysis for the global burden of disease study 2013. Lancet. 2014;384;980-1004.

7. Jowett M. Safe motherhood interventions in lowincome countries: an economic justification and evidence of cost effectiveness. Health policy. 2000;53:201-28.

8. Khan KS, Wojdyla D, Say L, Gulmezoglu AM, Van Look PF. WHO analysis of causes of maternal death: a systematic review. Lancet. 2006;367:1066-74.

9. Li XF, Fortney JA, Kotelchuck M, Gloyer LH. The postpartum period: the key to maternal mortality. Int J Gynecol Obstet. 1996;54(1):1-10.

10. Thaddeus S, Maine D. Too far to walk: maternal mortality in context. Soc Sci Med. 1994;38:1091110.
11. McCarthy J, Maine D. A framework for analyzing the determinants of maternal mortality. Stud Fam Plann. 1992;23(1):23-33.

12. Fawcus S, Mbizvo M, Lindmark G, Nystrom L. A community-based investigation of avoidable factors for maternal mortality in Zimbabwe. Stud Fam Plann. 1996:319-27.

13. Paxton A, Maine D, Freedman L, Fry D, Lobis S. The evidence for emergency obstetric care. Int $\mathrm{J}$ Gynecol Obstet. 2005;88:181-93.

14. El-Henawy A. Current situation, progress and prospects of health for all in Egypt. East Mediterr Health j. 2000;6(4):816-21.

15. Egypt $\mathrm{MoH}$, Population. National maternal mortality study: Egypt 2000: report of findings and conclusions. Egypt: directorate of maternal and child health care, ministry of health and population; 2001.

16. Karlsen S, Say L, Souza JP, Hogue CJ, Calles DL, Gulmezoglu AM, et al. The relationship between maternal education and mortality among women giving birth in health care institutions: analysis of the cross sectional WHO global survey on maternal and perinatal health. BMC Public Health. 2011;11:606.

17. Gabrysch S, Campbell OM. Still too far to walk: literature review of the determinants of delivery service use. BMC pregnancy and childbirth. 2009;9:34.

18. Fathalla MF. Human rights aspects of safe motherhood. Best Pract Res Clin Obstet Gynaecol. 2006;20(3):409-19.

Cite this article as: Abbas AM, Amin MT, Ali SS, Salem NZ. Maternal Mortality: a tertiary care hospital experience in upper Egypt. Int J Reprod Contracept Obstet Gynecol 2016;5:146671. 